\title{
Tomoelastography for non-invasive detection and treatment monitoring in acute appendicitis
}

\author{
Stephan Rodrigo Marticorena Garcia, Bernd Hamm, Ingolf Sack
}

Radiology, Charité Universitätsmedizin Berlin, Berlin, Germany

\section{Correspondence to}

Dr Stephan Rodrigo Marticorena Garcia,

stephan.marticorena-garcia@ charite.de

Accepted 25 July 2019
Check for updates

(c) BMJ Publishing Group Limited 2019. No commercial re-use. See rights and permissions. Published by BMJ.

To cite:
Marticorena Garcia SR,
Hamm B, Sack I. BMJ Case
Rep 2019;12:e230791.
doi:10.1136/bcr-2019-
230791

\section{SUMMARY}

Acute appendicitis is the most common cause of the acute abdomen syndrome and can be treated either surgically or conservatively with antibiotics. This case demonstrates the first time use of mechanics based MRI by tomoelastography with generation of quantitative maps of tissue stiffness (shear wave speed in $\mathrm{m} / \mathrm{s}$ ) and tissue fluidity (shear modulus loss angle, in rad) in a case of uncomplicated acute appendicitis with antibiotic treatment at (i) baseline, (ii) the end of treatment (EOT) and (iii) the 10 day follow-up after EOT. Baseline maps of stiffness and fluidity revealed to the naked eye the extent of intestinal inflammation by markedly increased values of stiffness and fluidity $(2.56 \pm 0.12 \mathrm{~m} / \mathrm{s}, 1.37 \pm 0.24 \mathrm{rad})$ compared with normal values, indicating the immediate response to antibiotic treatment at EOT $(1.47 \pm 0.28 \mathrm{~m} / \mathrm{s}$, $0.80 \pm 0.11 \mathrm{rad})$ and persistent normalisation at followup ( $1.54 \pm 0.22 \mathrm{~m} / \mathrm{s}, 0.92 \pm 0.22 \mathrm{rad})$. Tomoelastography is a non-invasive, quantitative imaging method for mechanics based characterisation and follow-up of acute appendicitis.

\section{BACKGROUND}

Acute appendicitis is the most common cause of acute abdomen. ${ }^{1}$ Its clinical presentation varies, from a simple or uncomplicated form with local inflammation of the appendix to complicated appendicitis with extensive inflammation leading to gangrene or abscess formation or even causing perforation. $^{2}$ Open or laparoscopic appendectomy used to be the standard therapy for appendicitis. Recently, various randomised controlled trials ${ }^{3-8}$ and meta-analyses ${ }^{9-14}$ have confirmed that antibiotic administration is an effective and safe primary

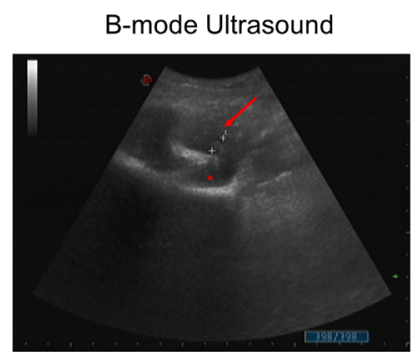

Figure 1 B mode ultrasound images of acute appendicitis (arrow) demonstrating focal, oedematous wall thickening with a maximum appendix diameter of $7.6 \mathrm{~mm}$ (white crosses) and surrounding fluid accumulation (asterisk).
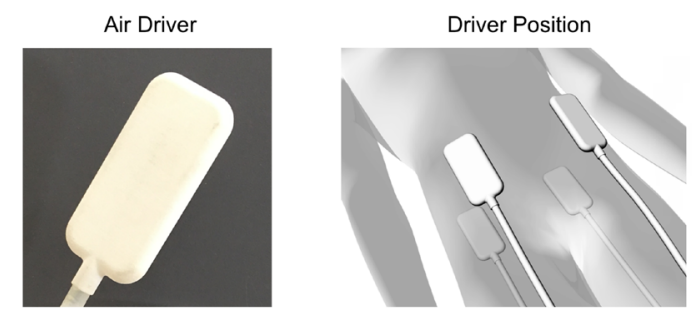

Figure 2 Left: Example of a custom made pressurised air driver. Right: Driver position around the lower abdomen, two anterior (white) and two posterior (grey).

treatment option for early uncomplicated appendicitis. Ultrasound (US) and CT are the primary imaging modalities to diagnose acute appendicitis. ${ }^{15-17}$ However, quantification is only based on size measurements and qualitative description of morphological changes. Tomoelastography has been recently introduced as an elastography method based on MRI and provides quantitative mechanical parameters of biological soft tissues. ${ }^{18} 19$

We report a case of first time use of tomoelastography for the diagnosis of uncomplicated appendicitis and monitoring of non-operative antibiotic treatment. The case demonstrates that tomoelastography provides useful quantitative imaging markers for the detection and assessment of the extent of local intestinal inflammation.

\section{CASE PRESENTATION}

A 34-year-old man with no family history of abdominal diseases or cancer presented to a physician, subspecialised in gastroenterology, with acute pain in the lower right abdomen and slight fever $\left(37.7^{\circ} \mathrm{C}\right)$. Symptoms began 2 days earlier with undefined and dull pain in the upper abdomen and subsequent migration into the lower right abdomen. The character of the pain changed to stabbing pain within 1 day of symptom onset. Examination revealed local tenderness and slight hyperthermia in the right lower abdominal quadrant and overall paleness. There was no nausea, vomiting or diarrhoea. The patient was normotensive with a blood pressure of $120 / 80 \mathrm{~mm} \mathrm{Hg}$ and a heart rate of $60 \mathrm{bpm}$. The Alvarado score, a clinical scoring system combining history, physical examination and laboratory tests ${ }^{20}$ with good diagnostic accuracy in men, ${ }^{21}$ was 6 , suggesting uncomplicated appendicitis. 

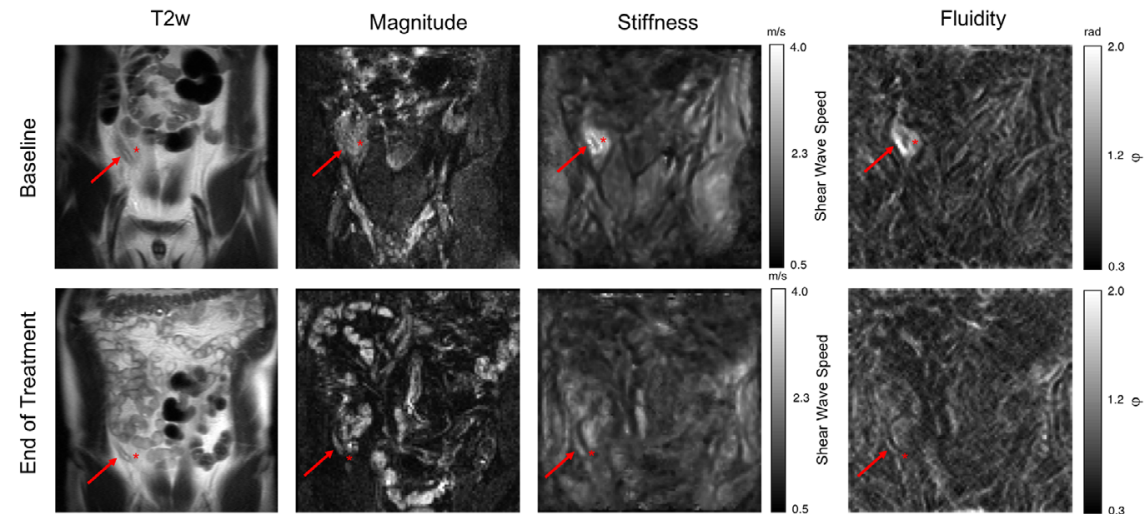

Figure 3 Coronal T2 weighted (T2w), magnitude, stiffness and fluidity images of the appendix (arrow) in grey scale at baseline (top row) and at the end of antibiotic treatment (bottom row). At baseline, the inflammatory appendix (arrow) and the surrounding tissue (asterisk) were significantly stiffer and more fluid than after antibiotic treatment. Inflammatory areas in stiffness and fluidity maps are demarcated with higher contrast from surrounding healthy soft tissue compared with $\mathrm{T} 2 \mathrm{w}$ images, allowing a clear identification of the extent of inflammatory involvement. Grey scale for stiffness: bright=stiff, dark=soft; grey scale for fluidity: bright=high fluidity, dark=low fluidity.

\section{INVESTIGATIONS}

Blood tests showed an increased $\mathrm{C}$ reactive protein level of $102 \mathrm{mg} / \mathrm{L}$ (reference range $<5 \mathrm{mg} / \mathrm{L}$ ) and an elevated leucocyte count of 10.9/nl (reference range 3.7-10.1/nl). Other standard chemical laboratory results were normal.

Standard US imaging (mylabXvision50, 3.5-MHz transducer) revealed focal, oedematous wall thickening of the appendix with surrounding fluid accumulation. The maximum appendix diameter was $7.6 \mathrm{~mm}$, which is unspecific regarding the underlying pathology (figure 1). Due to the inherent limitations of US, such as restricted field of view, limited penetration depth and degradation by bowel gas artefacts, a further quantitative analysis of morphological features or elastographic examinations was not possible.

Following this diagnosis and unspecific US findings, the patient underwent an MRI examination. After standard T1 and T2 weighted MRI acquisition for anatomical correlation, we used multifrequency MRI elastography with tomoelastography postprocessing. ${ }^{19}$ The latter was performed at three time points: (i) baseline, (ii) end of treatment (EOT) and (iii) follow-up 10 days after EOT. We used four mechanical stimulation frequencies of $40,50,60$ and $70 \mathrm{~Hz}$ induced by a custom made pressurised air driver, which was gently wrapped around the abdomen of the patient (see figure 2). Single shot, spin echo, echo planar imaging
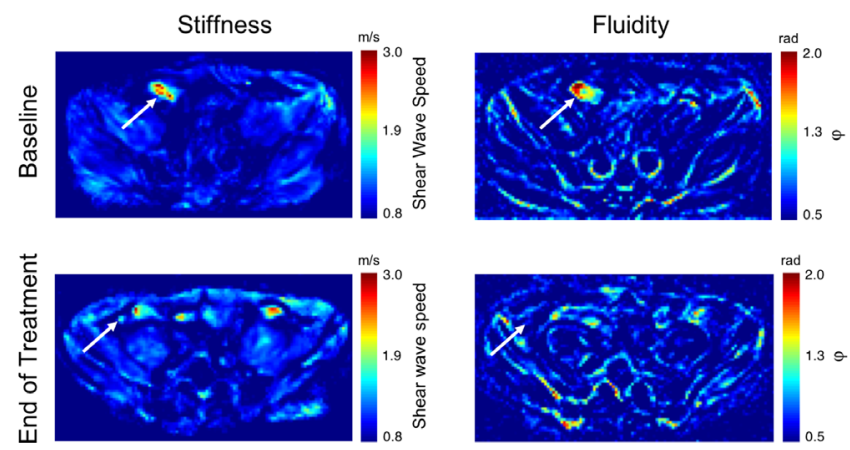

Figure 4 Axial view of coloured stiffness and fluidity maps at baseline (top row) and at the end of antibiotic treatment (bottom row). Acute appendicitis (arrow) is characterised by high stiffness and fluidity. Colour bar for stiffness: red=stiff, blue=soft; colour bar for fluidity: red=high fluidity, blue=low fluidity. was performed in coronal and axial orientation at $1.5 \mathrm{~T}$ (Sonata, Siemens). Tomoelastography provides full field of view maps of shear wave speed (SWS in $\mathrm{m} / \mathrm{s}$ ) as a surrogate of stiffness as well as the loss angle of the complex shear modulus ( $\phi$ in $\mathrm{rad}$ ). $\phi$ is related to the solid-fluid behaviour of the tissue and potentially important in any disease associated with water accumulation or oedema. Since larger values $(\phi>0.78)$ are considered to be dominated by fluid tissue properties, $\phi$ is also referred to as 'fluidity'. The total acquisition time of the tomoelastography scan was $4 \mathrm{~min}$ with the patient breathing normally.

At baseline (before treatment), SWS and $\phi$ were increased in the appendix $(2.56 \pm 0.12 \mathrm{~m} / \mathrm{s}, 1.37 \pm 0.24 \mathrm{rad})$ and the surrounding tissue $(2.38 \pm 0.16 \mathrm{~m} / \mathrm{s}, 1.32 \pm 0.28 \mathrm{rad})$. The increase in SWS and $\phi$ is apparent to the naked eye when

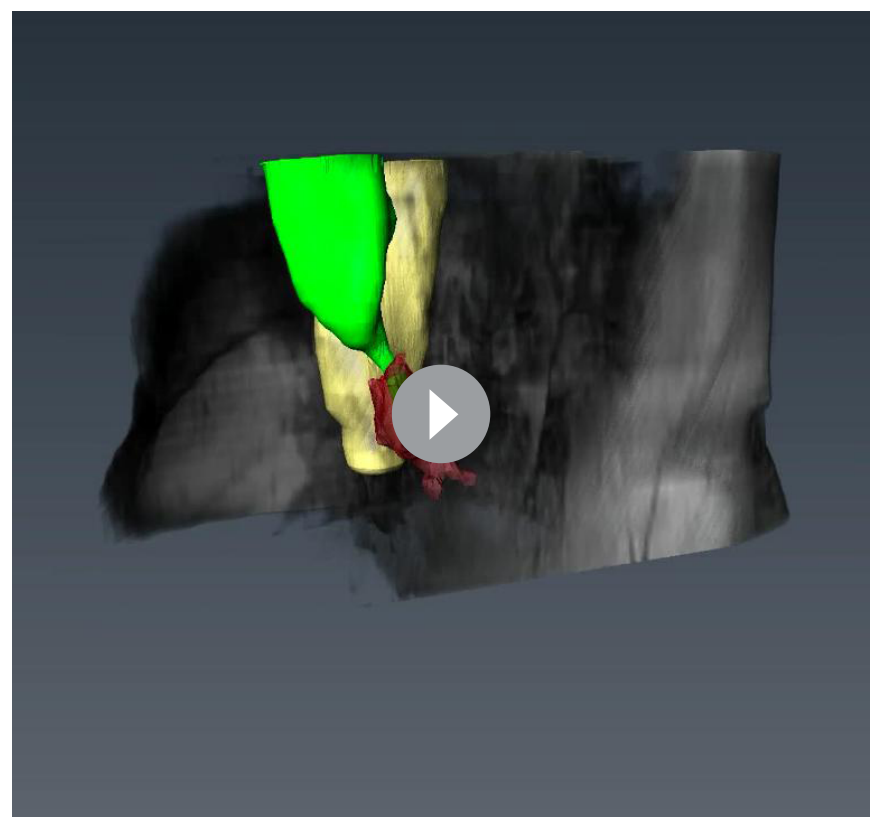

Video 1 Three-dimensional view of acute appendicitis at baseline (before treatment), fusion of three-dimensional T1 weighted and three-dimensional stiffness map reconstruction. Green=caecum with appendix, red=inflammation (stiff area based on stiffness map), yellow=iliopsoas muscle. 
A

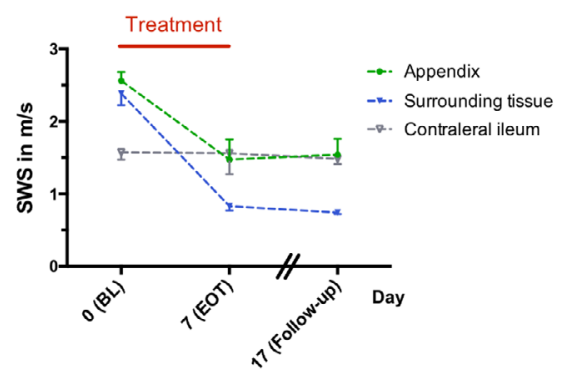

B

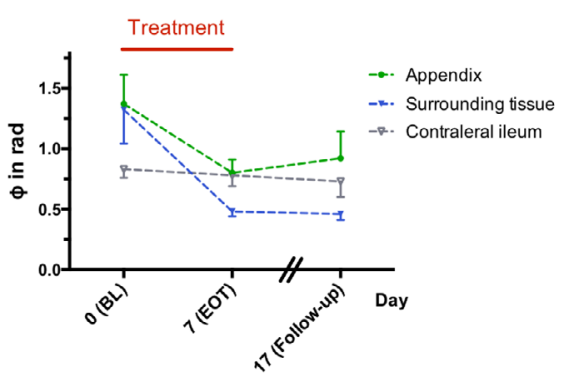

Figure 5 Development of stiffness (A) and fluidity (B) over time in a patient with acute appendicitis. At baseline (BL), shear wave speed (SWS) $(A)$ and shear modulus loss angle $(\phi)(B)$ of the acutely inflamed appendix (green line) and the inflamed surrounding soft tissue (blue line) were significantly higher than in the contralateral ileum (healthy, grey line). At the end of antibiotic treatment (EOT), SWS (A) and $\phi$ (B) of the appendix decreased to those of the healthy ileum and remained stable at follow-up (10 days after EOT). Healthy surrounding soft tissue has a lower SWS (A) and $\phi(B)$ than healthy appendix and ileum. Red bar=treatment period.

looking at the tomoelastography maps presented in figures 3 and 4. Intriguingly, a wider inflammatory area of the appendix and surrounding soft tissue with elevated stiffness and fluidity and relatively sharp boundaries is visible in these maps. The large area of elevated stiffness and fluidity indicates widespread inflammation and related oedema associated with acute appendicitis. A three-dimensional stiffness map reconstruction of the inflammation (red area) is provided in video 1 . Normal contralateral intestine (ileum) was used as reference tissue. In this unaffected region, the tissue was softer and less fluid (SWS 1.57 $\pm 0.10 \mathrm{~m} / \mathrm{s}, \phi=0.83 \pm 0.07 \mathrm{rad})$. Stiffness and fluidity values are summarised in figure 5. No signs of perforation were detected by US or MRI.

\section{TREATMENT}

Because the clinical presentation suggested a simple and uncomplicated appendicitis, the patient was treated with oral antibiotics (daily dose of $800 \mathrm{mg}$ metronidazole and $1000 \mathrm{mg}$ clarithromycin) for 1 week.

\section{OUTCOME AND FOLLOW-UP}

$\mathrm{C}$ reactive protein was normalised at $\mathrm{EOT}(4 \mathrm{mg} / \mathrm{L}$; reference range $<5 \mathrm{mg} / \mathrm{L}$ ). The patient first reported subjective symptom relief 5 days after starting antibiotics. At EOT, the patient reported subjective well being (Alvarado score of 0 ) apart from a slight pulling sensation in the lower right abdomen (region of appendix). Pulling ceased 10 days after EOT, and the patient was considered cured.

Consistent with the patient's clinical presentation and laboratory results, tomoelastography showed a significant reduction of stiffness and fluidity in the appendix (SWS and $\phi, 1.47 \pm 0.28$ $\mathrm{m} / \mathrm{s}, 0.80 \pm 0.11 \mathrm{rad}$, respectively) and the surrounding soft tissue (SWS and $\phi, 0.83 \pm 0.06 \mathrm{~m} / \mathrm{s}, 0.78 \pm 0.09 \mathrm{rad}$, respectively at EOT) (see figures 3 and 4). Follow-up 10 days after EOT showed persistent normalisation of these parameters for both the appendix (SWS and $\phi, 1.54 \pm 0.22 \mathrm{~m} / \mathrm{s}, 0.92 \pm 0.22 \mathrm{rad}$, respectively) and the surrounding soft tissue (SWS and $\phi, 0.74 \pm 0.02$, $0.46 \pm 0.05 \mathrm{rad}$, respectively). Stiffness and fluidity values over the entire course of disease are illustrated in figure 5. Wall oedema seen in tomoelastography maps decreased to a diameter of $5.8 \mathrm{~mm}$ at EOT and remained stable over 10 days after EOT $(5.9 \mathrm{~mm})$.

\section{DISCUSSION}

This case demonstrates the clinical value of MRI based tomoelastography for the diagnostic characterisation of acute appendicitis and monitoring the treatment response. To the best of our knowledge, this is the first report of MRI elastography of the intestine in a patient. Our tomoelastography technique sufficiently resolved small intestinal structures, including the appendix, while conventional MR elastography often suffers from single frequency wave interferences and cannot resolve viscoelasticity details on the scale of single pixels. One other study investigated acute appendicitis using US elastography and showed a similar increase in stiffness within the appendix ( $25.0 \mathrm{kPa}$ converted to $2.89 \mathrm{~m} / \mathrm{s} \mathrm{SWS}$ ) versus the surrounding tissue $(10.4 \mathrm{kPa}$ converted to $1.86 \mathrm{~m} / \mathrm{s}) .{ }^{22}$ However, this method is often limited by $\mathrm{B}$ mode artefacts due to bowel gas or a retrocoecal appendix.

Surgery is recommended as firstline treatment of acute appendicitis by current guidelines and is considered the gold standard despite its invasiveness. ${ }^{1523}$ Nevertheless, conservative treatment based on antibiotics is increasingly being used and regarded as a valid alternative in uncomplicated cases. ${ }^{3-8} 1523$ Therefore, it is likely that there will be an increasing demand for quantitative imaging methods sensitive to inflammation in the intestinal region. $^{24}$

The initial diagnosis and monitoring of patients with appendicitis are still challenging due to the highly variable clinical and/or laboratory presentation. ${ }^{24}$ Being widely available at low cost, US is considered the firstline imaging modality. ${ }^{16}$ However, US is operator dependent and fails in ruling out appendicitis in patients with low grade inflammation and normal B mode appearance. ${ }^{25}$ The diagnostic accuracy of CT and MRI is comparable and superior to US but both modalities lack specificity in distinguishing uncomplicated and complicated appendicitis while CT is also limited by the use of ionising radiation and MRI by the fact that a Gd based contrast agent is required to detect inflammation. ${ }^{8}$ Furthermore, most imaging examinations are non-quantitative, limiting their diagnostic value in follow-up examinations and treatment monitoring. ${ }^{1726} 27$ Intestinal tomoelastography addresses this diagnostic challenge by offering a new mechanics based contrast, allowing quantitative identification of the extent of inflammation on the basis of increased tissue stiffness and fluidity. Moreover, it does not involve exposure to radiation or contrast agents and might therefore be of 


\section{Patient 's perspective}

The disease started with diffuse stomach pain lasting for about 1-4 hours. First, I attributed it to eating spicy food. Later that evening, the pain relocated to the lower right abdomen. The pain remained stable over the next 2 days, and I measured a slightly elevated temperature of $37.7^{\circ}$, so that I decided to go to the gastroenterologic doctor's office. A clinical and abdominal ultrasound examination and blood collection were performed by the doctor. Due to the outpatient setting it took 3 days before I was informed about the blood results. The doctor diagnosed an acute appendicitis based on the clinical examination and the US findings.

The doctor explained the diagnosis to me and informed me in detail about the treatment options, including possible side effects. I had the choice between surgery and treatment with antibiotics. I opted to decline surgery and considered the antibiotics a better alternative. I never had an operation before and I feared such an invasive procedure.

On the same evening, I felt uncertain regarding my decision and began to think that an operation might be better after all. I was aware that failure of antibiotic treatment could lead to the complication of a perforation and I was afraid that an inflammation could increase and get worse. I had to choose between a planned surgery or a possible emergency surgery if antibiotic treatment failed.

Tomoelastography confirmed the diagnosis of uncomplicated appendicitis. The external vibration needed for creating the waves was well tolerable and adapted to my subjective feeling. It felt like a cell phone vibration, but it was better tolerable than walking. The radiologist showed the elastograms to me. My anatomical orientation was very poor, but I could follow the radiologist, and the very bright inflammatory spot was clearly visible to me without any deeper knowledge. After tomoelastography, I felt reassured and decided to stick to the antibiotic therapy. On the following day, the inflammation was still apparent but it did not get worse. So I continued with the antibiotics.

After 7 days on antibiotics, I was uncertain about the next steps after the end of treatment. A second blood test was performed at the end of treatment. These results were normal. Furthermore, another tomoelastography was performed after treatment, and the radiologist reassured me that everything looked normal again. The stiffness values of the appendix were similar to those elsewhere in the intestine. Both results confirmed the success of antibiotic treatment, and I felt much reassured and comfortable although a slight pulling sensation was still apparent in the lower right abdomen. After 10 days, the feeling of pulling disappeared, and I had no further physical restrictions.

Now that I had my first experience with a serious disease I am very happy that I had a good alternative treatment option and was spared surgery. I believe that everything in our body has its function and should be preserved as long as possible. In my case imaging with display of changes I could see gave me the confidence I needed to understand that antibiotic treatment was successful.

diagnostic value for clinical detection and characterisation of inflammatory lesions in undecided cases, pregnant women and children. Furthermore, tomoelastography could also be used for monitoring the response to antibiotic treatment as patients
Learning points

- Acute appendicitis is characterised by higher stiffness and fluidity.

- Tomoelastography is a promising non-invasive and quantitative method for identification of acute appendicitis and confirmation of an uncomplicated stage.

- Tomoelastography provides quantitative values allowing follow-up for monitoring the response to antibiotic treatment.

- Cut-offs are needed for therapeutic decision making and could be generated for different stages of appendicitis in the future.

not responding to antibiotics face the risk of developing severe complications, such as perforation and peritonitis.

Acknowledgements The authors would like to acknowledge Dr Lutz LiebichBartholain for providing ultrasound images and permission for publication, Dr Zully Maritza Ritter and Dr Jürgen Braun for their technical support, and the patient for his continued engagement and support.

Contributors SRMG and IS: conception, design, and analysis and interpretation of the data. SRMG: drafting the article. SRMG, BH and IS: revising the manuscript critically for important intellectual content and final approval of the version published.

Funding This study was funded by Bundesministerium für Bildung und Forschung (grant No: LiSyM 031L0057) and Deutsche Forschungsgemeinschaft (grant No: BIOQIC GRK 2260, SFB 1340).

Competing interests None declared.

Patient consent for publication Obtained.

Provenance and peer review Not commissioned; externally peer reviewed.

\section{REFERENCES}

1 Buckius MT, McGrath B, Monk J, et al. Changing epidemiology of acute appendicitis in the United States: study period 1993-2008. J Surg Res 2012;175:185-90.

2 Becker P, Fichtner-Feigl S, Schilling D. Clinical management of appendicitis. Visc Med 2018:34:453-8.

3 Eriksson S, Granström L. Randomized controlled trial of appendicectomy versus antibiotic therapy for acute appendicitis. Br J Surg 1995;82:166-9.

4 Hansson J, Körner U, Khorram-Manesh A, et al. Randomized clinical trial of antibiotic therapy versus appendicectomy as primary treatment of acute appendicitis in unselected patients. Br J Surg 2009;96:473-81.

5 Salminen P, Paajanen H, Rautio T, et al. Antibiotic therapy vs appendectomy for treatment of uncomplicated acute appendicitis: the APPAC randomized clinical trial. JAMA 2015;313:2340-8.

6 Styrud J, Eriksson S, Nilsson I, et al. Appendectomy versus antibiotic treatment in acute appendicitis. a prospective multicenter randomized controlled trial. World J Surg 2006;30:1033-7

7 Talan DA, Saltzman DJ, Mower WR, et al. Antibiotics-first versus surgery for appendicitis: a US pilot randomized controlled trial allowing outpatient antibiotic management. Ann Emerg Med 2017;70:1-11.

8 Vons C, Barry C, Maitre S, et al. Amoxicillin plus clavulanic acid versus appendicectomy for treatment of acute uncomplicated appendicitis: an open-label, non-inferiority, randomised controlled trial. Lancet 2011;377:1573-9.

9 Findlay JM, Kafsi JE, Hammer C, et al. Nonoperative management of appendicitis in adults: a systematic review and meta-analysis of randomized controlled trials. J Am Coll Surg 2016;223:814-24.

10 Harnoss JC, Zelienka I, Probst P, et al. Antibiotics versus surgical therapy for uncomplicated appendicitis: systematic review and meta-analysis of controlled trials (PROSPERO 2015: CRD42015016882). Ann Surg 2017;265:889-900.

11. Poprom N, Numthavaj P, Wilasrusmee C, et al. The efficacy of antibiotic treatment versus surgical treatment of uncomplicated acute appendicitis: Systematic review and network meta-analysis of randomized controlled trial. Am J Surg 2019;218:192-200.

12 Rollins KE, Varadhan KK, Neal KR, et al. Antibiotics versus appendicectomy for the treatment of uncomplicated acute appendicitis: an updated meta-analysis of randomised controlled trials. World J Surg 2016:40:2305-18.

13 Sallinen V, AkI EA, You JJ, et al. Meta-analysis of antibiotics versus appendicectomy for non-perforated acute appendicitis. Br J Surg 2016;103:656-67. 
14 Varadhan KK, Neal KR, Lobo DN. Safety and efficacy of antibiotics compared with appendicectomy for treatment of uncomplicated acute appendicitis: meta-analysis of randomised controlled trials. BMJ 2012;344:e2156.

15 Di Saverio S, Birindelli A, Kelly MD, et al. WSES Jerusalem guidelines for diagnosis and treatment of acute appendicitis. World J Emerg Surg 2016;11:34.

16 Dirks K, Calabrese E, Dietrich CF, et al. EFSUMB position paper: recommendations for gastrointestinal ultrasound (GIUS) in acute appendicitis and diverticulitis. Ultraschall Med 2019:40:163-75.

17 Kim K, Kim YH, Kim SY, et al. Low-dose abdominal CT for evaluating suspected appendicitis. N Engl J Med 2012;366:1596-605.

18 Dittmann F, Tzschätzsch H, Hirsch S, et al. Tomoelastography of the abdomen: tissue mechanical properties of the liver, spleen, kidney, and pancreas from single MR elastography scans at different hydration states. Magn Reson Med 2017;78:976-83.

19 Tzschätzsch H, Guo J, Dittmann F, et al. Tomoelastography by multifrequency wave number recovery from time-harmonic propagating shear waves. Med Image Anal 2016;30:1-10.

20 Alvarado A. A practical score for the early diagnosis of acute appendicitis. Ann Emerg Med 1986;15:557-64.
21 Ohle R, O'Reilly F, O'Brien KK, et al. The Alvarado score for predicting acute appendicitis: a systematic review. BMC Med 2011;9:139.

22 Cha SW, Kim IY, Kim YW. Quantitative measurement of elasticity of the appendix using shear wave elastography in patients with suspected acute appendicitis. PLOS One 2014;9:e101292.

23 Baird DLH, Simillis C, Kontovounisios C, et al. Acute appendicitis. BMJ 2017;357:j1703.

24 Gorter RR, Eker HH, Gorter-Stam MA, et al. Diagnosis and management of acute appendicitis. EAES consensus development conference 2015. Surg Endosc 2016;30:4668-90.

25 Shogilev DJ, Duus N, Odom SR, et al. Diagnosing appendicitis: evidence-based review of the diagnostic approach in 2014. West J Emerg Med 2014;15:859-71.

26 Hoffmann M, Anthuber M. [Rational diagnostics of acute appendicitis]. Chirurg 2019;90:173-7.

27 Repplinger MD, Levy JF, Peethumnongsin E, et al. Systematic review and meta-analysis of the accuracy of MRI to diagnose appendicitis in the general population. J Magn Reson Imaging 2016;43:1346-54.

Copyright 2019 BMJ Publishing Group. All rights reserved. For permission to reuse any of this content visit https://www.bmj.com/company/products-services/rights-and-licensing/permissions/

BMJ Case Report Fellows may re-use this article for personal use and teaching without any further permission.

Become a Fellow of BMJ Case Reports today and you can:

- Submit as many cases as you like

- Enjoy fast sympathetic peer review and rapid publication of accepted articles

- Access all the published articles

Re-use any of the published material for personal use and teaching without further permission

\section{Customer Service}

If you have any further queries about your subscription, please contact our customer services team on +44 (0) 2071111105 or via email at support@bmj.com.

Visit casereports.bmj.com for more articles like this and to become a Fellow 